\title{
Blast Wave Parameters for Spherical Explosives Detonation in Free Air
}

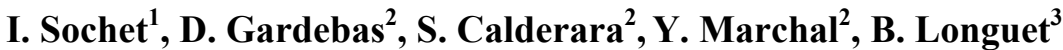 \\ ${ }^{1}$ Ecole Nationale Supérieure d'Ingénieurs de Bourges, Institut PRISME, Bourges, France \\ ${ }^{2}$ Institut de Recherche Criminelle de la Gendarmerie Nationale (IRCGN), \\ Division Criminalistique Physique et Chimie, \\ Rosny-sous-Bois, France \\ ${ }^{3}$ Direction Générale de l'Armement (DGA) Techniques Terrestres, Bourges, France \\ E-mail: isabelle.sochet@ensi-bourges.fr \\ Received May 24, 2011; revised July 19, 2011; accepted July 25, 2011
}

\begin{abstract}
Several formulations have been published to define the characteristic parameters of an incident blast wave. In almost all previous work, the charge examined has been TNT explosive and overpressure has been the main parameter examined. In this paper, we describe an investigation based on three explosives, TNT, PETN and ANFO, which has been conducted by considering three parameters: overpressure, duration and impulse of the positive blast wave phase. Calculations of the three parameters were conducted using TM5-855 through the tool CONWEP and AUTODYN. The positive overpressures were calculated using the new forensic software ASIDE. The evolution of these blast wave parameters is expressed by combining the laws of two approaches: the forensic approach and the security approach. TNT equivalents are expressed in terms of pressure and impulse for the comparisons of ANFO and PETN.
\end{abstract}

Keywords: ANFO, Blast Wave, Duration, Explosive, Impulse, Overpressure, PETN, TNT

\section{Introduction}

To protect property and persons working on sites that handle, store or transport large quantities of flammable materials, it is necessary to estimate the effects of pressure resulting from an explosion, whether the explosion occurs at a close or a distant location. In this work, we consider explosions that are caused by pyrotechnic charges, whether intentional or accidental. Applications of pyrotechnic materials cover a variety of areas, including satellite technology, tactical and ballistic missiles, ammunitions, law enforcement, security, space launch vehicles, aerospace, automotive safety (airbags), railway signal devices and charges for the oil industry, demolition mines, quarries and buildings.

The objective of this work is to establish relationships to evaluate the mechanical effects of shock waves in free fields. We propose a dual approach using both forensic and security analyses. The forensic analysis uses observations of damage occurring at varying distances from the blast site to estimate the pressure and deduce the corresponding mass equivalent of TNT. The security approach, on the other hand, assumes that the mass of products stored or the equivalent TNT charge is known, such that the range of the resulting pressure, and therefore the resultant damage, must be determined.

This study was conducted for three explosives: TriNitroToluene (TNT), PEntaerythritol TetraNitrate (PETN) and Ammonium Nitrate/Fuel Oil (ANFO). TNT is a chemical compound that consists of an aromatic hydrocarbon crystal. In its refined form, TNT is relatively stable and is not sensitive to shock or friction. TNT is one of the most commonly used military and industrial explosives and is often used as a reference explosive. PETN is one of the most powerful explosives known. It is more sensitive to shock, friction and electrostatic discharge than TNT. It is mainly used as principal compound in some military explosives compositions (plastrite, semtex...), in detonators. In medicine, PETN is used as a vasodilator. ANFO is a highly explosive mixture consisting of ammonium nitrate and diesel fuel. The diesel fuel can be replaced by kerosene, gasoline or biofuels, but the cost and low volatility of diesel makes it ideal. Ammonium nitrate is water-soluble and very hy- 
groscopic, i.e., it readily absorbs water from the air. This absorption interferes with its ability to explode, and it must therefore be stored in a dry location. The popularity of ANFO is largely based on its low cost and high stability. Because of its relative ease of manufacture, its low cost compared to other types of similar explosives and the stability of its two components, ANFO has been used in several terrorist attacks (1970, University of Wisconsin-Madison; 1995, Oklahoma City).

In this study, we will first explore the thermochemical data on these explosives and then analyze the effects of blast waves.

\section{Thermodynamics of Explosions}

The explosives studied here highlight the difficulty in choosing an appropriate value for detonation energy.

"Heat of detonation" is defined as the heat of the reaction of the explosive that results in the detonation products. This heat does not include the heat generated by secondary reactions of the explosive or its products with air. There is some confusion in terminology related to detonation energy and heat of detonation, and the two are often used interchangeably. The heat of detonation is determined using calorimetric methods in a closed chamber and does not take into account the energy available from the highly compressed gases in the products, which can significantly contribute to the energy transmitted by a blast wave, as outlined in Scilly [1]. Therefore, the term "detonation energy" will hereafter be devoted to the calculated energy of the detonation of an explosive without considering the presence of air. Determination of the detonation energy is therefore based on prior knowledge of the decomposition of the explosive, which itself depends on the oxygen balance. Therefore, we will examine the oxygen balance of each of the explosives under consideration, as well as their decomposition-based models.

\subsection{Oxygen Balance}

The detonation of an explosive is an oxidative reaction that is based on the assumption that the available carbon, hydrogen and nitrogen are used solely for the formation of $\mathrm{CO}_{2}, \mathrm{H}_{2} \mathrm{O}$ and $\mathrm{N}_{2}$, respectively. The term oxygen balance $(\mathrm{OB})$ represents the concentration of oxygen atoms in an oxidant and indicates its oxidation potential. It expresses the number of molecules of oxygen remaining after the oxidation of $\mathrm{H}, \mathrm{C}, \mathrm{Mg}$, and $\mathrm{Al}$ into $\mathrm{H}_{2} \mathrm{O}$, $\mathrm{CO}_{2}, \mathrm{MgO}_{2}$ and $\mathrm{Al}_{2} \mathrm{O}_{3}$, respectively. The oxygen balance can be expressed more directly for a conventional explosive $\mathrm{C}_{\mathrm{a}} \mathrm{H}_{\mathrm{b}} \mathrm{N}_{\mathrm{c}} \mathrm{O}_{\mathrm{d}}$ by the following equation:

$$
\mathrm{OB}=\frac{1600 \times[\mathrm{d}-2 \times \mathrm{a}-\mathrm{b} / 2]}{\mathrm{MW}(\exp \text { losive })}
$$

where MW is the molecular weight. In this equation, the factor 1600 is the product of the molecular weight of oxygen expressed as a percentage $(\mathrm{MW}(\mathrm{O}) \times 100 \%)$.

The OB provides information about the products that are formed in the reaction. A positive value indicates an excess of oxygen in the explosive, whereas a negative value indicates oxygen levels that are insufficient to obtain a complete oxidation reaction. If the oxygen balance is strongly negative, there is not enough oxygen to form $\mathrm{CO}_{2}$, and toxic gases such as $\mathrm{CO}$ are formed instead. Note that the oxygen balance provides no information about the exchange of energy during the explosion.

Calculation of the oxygen balance of TNT and PETN is relatively simple because the chemical formulas of these materials are distinctly defined. However, this is not the case for ANFO, which is a mixture of ammonium nitrate (AN) and fuel oils (FO) in a ratio of 94:6 AN:FO.

Table 1 indicates that TNT has the highest oxygen deficit and that ANFO, PETN do not have sufficient oxygen to obtain complete oxidation reactions and form $\mathrm{H}_{2} \mathrm{O}$ and $\mathrm{CO}_{2}$. Hence, large amount of toxic gases like carbon monoxide will be present. In case of ANFO, the oxygen balance approaches zero. It means that the sensitivity, strength and brisance of ANFO tend to the maximum.

\subsection{Decomposition Rules}

To clarify the formation of decomposition products [2], a set of rules, known as the "Kistiakowsky-Wilson" rules (K-W rules), has been developed. The rules are used for explosives with moderate oxygen deficits and an oxygen balance greater than $-40 \%$ and can be described as fol-

Table 1. The oxygen balance of TNT, PETN and ANFO.

\begin{tabular}{cccc}
\hline Name & Chemical Formulation & OB (\%) $\left(\mathrm{g} \cdot \mathrm{mol}^{-1}\right)$ \\
\hline 2,4,6-Trinitrotoluene (TNT) & $\mathrm{C}_{7} \mathrm{H}_{5} \mathrm{~N}_{3} \mathrm{O}_{6}$ & 227 \\
Pentaerythritol Tetranitrate or Pentrite (PETN) & $\mathrm{C}_{5} \mathrm{H}_{8} \mathrm{~N}_{4} \mathrm{O}_{12}$ & 316 \\
Ammonium Nitrate/ Fuel Oil (ANFO) & $\mathrm{C}_{0.365} \mathrm{H}_{4.713} \mathrm{~N}_{2} \mathrm{O}_{3}[3,4]$ & 85.1 \\
\hline
\end{tabular}


lows:

1) First, the carbon atoms are converted into $\mathrm{CO}$.

2) If oxygen remains, then hydrogen is oxidized into water.

3) If oxygen still remains, then $\mathrm{CO}$ is oxidized to $\mathrm{CO}_{2}$.

4) All of the nitrogen is converted to $\mathrm{N}_{2}$.

For explosives with a lower OB, the modified K-W rules are used. The modified rules are as follows:

1) The hydrogen atoms are converted into water.

2) If oxygen remains, then carbon is converted into $\mathrm{CO}$.

3) If oxygen still remains, then $\mathrm{CO}$ is oxidized to $\mathrm{CO}_{2}$.

4) All of the nitrogen is converted to $\mathrm{N}_{2}$.

The Springall-Roberts rules (S-R rules), which are described below, add two additional conditions to the K-W rules:

5) One-third of the $\mathrm{CO}$ formed is converted into carbon and $\mathrm{CO}_{2}$.

6) One-sixth of the original amount of $\mathrm{CO}$ is converted to carbon and into water with the addition of hydrogen.

According to Scilly [1], the decomposition equation recommended by Kamlet and Jacob (the K-J rule) can be obtained as follows:

$$
\begin{aligned}
\mathrm{C}_{\mathrm{a}} \mathrm{H}_{\mathrm{b}} \mathrm{N}_{\mathrm{c}} \mathrm{O}_{\mathrm{d}} \rightarrow & (a-0.5 \times \mathrm{d}+0.25 \times \mathrm{b}) \mathrm{C} \\
& +(0.5 \times \mathrm{d}-0.25 \times \mathrm{b}) \mathrm{CO}_{2} \\
& +(0.5 \times \mathrm{b}) \mathrm{H}_{2} \mathrm{O}+(0.5 \times \mathrm{c}) \mathrm{N}_{2}
\end{aligned}
$$

In this scheme, $\mathrm{CO}$ is not formed preferentially and $\mathrm{CO}_{2}$ is the only oxidation product of carbon. In addition, $\mathrm{H}_{2} \mathrm{O}$ is always formed at the beginning of the reaction.

Kinney [6] considers that all of the oxygen is incorporated into carbon monoxide, which implies the following chemical equation in the case of TNT:

$$
\mathrm{C}_{7} \mathrm{H}_{5} \mathrm{~N}_{3} \mathrm{O}_{6} \rightarrow \mathrm{C}+6 \mathrm{CO}+2.5 \mathrm{H}_{2}+1.5 \mathrm{~N}_{2}
$$

Table 2 below summarizes the products formed by each of the explosives considering the different rules of decomposition.

\subsection{Detonation Energy}

The explosives studied here highlight the complexity that exists in identifying the correct value of detonation energy, i.e., whether the value should be chosen from the literature or if it should be calculated. Generally, a ratio of 1.5 exists between the minimum and maximum values, depending on whether the values are obtained from experiments or calculated and whether water is considered a liquid or a gas reaction products. Moreover, the composition of products in an actual detonation is not always the same for a given explosive. Factors such as density, temperature, initial degree of confinement, particle size and morphology and the size and shape of the load affect the pressure and temperature behind the detonation front, where the products undergo rapid expansion that is not always balanced.

The detonation energy can be calculated either from the Helmholtz free energy [7] or from the reaction enthalpy. In the first case, the detonation energy is the energy transmitted by the explosive shock wave and is associated with the work done in the expansion of gases produced during the explosion, which is described by

$\int_{\text {initial }}^{\text {final }} P \cdot \Delta V$. By applying the first and second laws of thermodynamics, the change in the Helmholtz free energy can be used to calculate the energy of explosion expressed in terms of internal energy $\Delta U$ and entropy $\Delta S$ as follows:

$$
\Delta F=\Delta U-T \cdot \Delta S, \text { where } \Delta U=\Delta H-R \cdot T \cdot \Delta n
$$

and $\Delta H=\Delta H_{p}-\Delta H_{r} ; \Delta n=n_{p}-n_{r} ; \Delta S=\Delta S_{p}-\Delta S_{r}$

Here subscripts $p$ and $r$ represents respectively the products and the reactive.

In the second case, the reaction energy can be calcu-

\begin{tabular}{|c|c|c|c|c|c|c|c|}
\hline \multirow{2}{*}{ Explosive } & \multirow{2}{*}{ Rule } & \multicolumn{6}{|c|}{ Products (mole number) } \\
\hline & & $\mathrm{C}$ & $\mathrm{CO}$ & $\mathrm{CO}_{2}$ & $\mathrm{H}_{2}$ & $\mathrm{H}_{2} \mathrm{O}$ & $\mathrm{N}_{2}$ \\
\hline \multirow[t]{2}{*}{$\mathrm{C}_{7} \mathrm{H}_{5} \mathrm{~N}_{3} \mathrm{O}_{6}$} & S-R & 3 & 3 & 1 & 1.5 & 1 & 1.5 \\
\hline & $\mathrm{K}-\mathrm{J}$ & 5.25 & 0 & 1.75 & 0 & 2.5 & 1.5 \\
\hline \multirow{2}{*}{$\mathrm{C}_{5} \mathrm{H}_{8} \mathrm{~N}_{4} \mathrm{O}_{12}$} & $\mathrm{~K}-\mathrm{W}$ & 0 & 2 & 3 & 0 & 4 & 2 \\
\hline & S-R or K-J & 1 & 0 & 4 & 0 & 4 & 2 \\
\hline $\mathrm{C}_{0.365} \mathrm{H}_{4.713} \mathrm{~N}_{2} \mathrm{O}_{3}$ & S-R or K-J & 0.043 & 0 & 0.322 & 0 & 2.356 & 1 \\
\hline $\mathrm{C}_{0.336} \mathrm{H}_{4.656} \mathrm{~N}_{2} \mathrm{O}_{3}$ & S-R or K-J & 0 & 0 & 0.336 & 0 & 2.328 & 1 \\
\hline
\end{tabular}
lated by the enthalpy change involved in the chemical reaction between the standard state products and reactive.

Table 2. Decomposition of TNT, PETN and ANFO. 
Thus, calculation of the detonation energy was conducted for different patterns of decomposition in TNT and PETN by considering 1) water molecules in the gaseous and liquid states, and 2) the data available in the literature for enthalpies and entropies of formation of explosives and detonation products. Only the enthalpies and entropies of formation for TNT and PETN are reported in Table 3 below.

The results of the calculations for each configuration show that the detonation energy calculated using the free energy is higher than that obtained using the reaction enthalpy regardless of the explosive studied, and both of these calculations are higher than the average value in the literature. Moreover, the energies are greater if water is considered in the liquid phase. However, regardless of the enthalpy of formation selected, the results are always in the same energy range for a given decomposition rule.

Tongchang et al. [8] have conducted experimental determinations for TNT using a calorimeter in which the cylindrical bomb had an internal volume of $5 \mathrm{~L}$ and could support a pressure of $200 \mathrm{MPa}$. The experiments were performed on maximum loads of $50 \mathrm{~g}$. The explosive force was measured as a function of the nature of the cartridge (porcelain, brass) and its thickness. All tests resulted in a value between $-4.31 \mathrm{MJ} \cdot \mathrm{kg}^{-1}$ and -4.40 $\mathrm{MJ} \cdot \mathrm{kg}^{-1}$ Finally, it should be emphasized that these values correlate with the values used by Gelfand $(-4.517$ $\left.\mathrm{MJ} \cdot \mathrm{kg}^{-1}\right)$ [9], Baker (-4.520 $\left.\mathrm{MJ} \cdot \mathrm{kg}^{-1}\right)$ [10], Pförtner $\left(-4.686 \mathrm{MJ} \cdot \mathrm{kg}^{-1}\right)$ [11] and Lannoy $\left(-4.690 \mathrm{MJ} \cdot \mathrm{kg}^{-1}\right)$ [3], in addition to the value proposed by Trelat [12] $(-4.600$ $\mathrm{MJ} \cdot \mathrm{kg}^{-1}$ ) that was obtained using the average of the Baker [10] and Lannoy [3] results. Other detonation energy values are quoted by Filler [4], including the energy calculated in the Encyclopedia of Chemical Technology $\left(-3.87 \mathrm{MJ} \cdot \mathrm{kg}^{-1}\right)$ [4], the measurement results from Tonegutti [4] that assume a $2 \mathrm{~g}$ charge with a conventional calorimeter (detonation energy $-3.21 \mathrm{MJ} \cdot \mathrm{kg}^{-1}$ ) and the measurements by the Armaments Research Establish- ment for a load of $100 \mathrm{~g}\left(-4.535 \mathrm{MJ} \cdot \mathrm{kg}^{-1}\right)$. Omang et al. [13] used a detonation energy value of $-4.26 \mathrm{MJ} \mathrm{kg}^{-1}$ to characterize the propagation of shock waves following detonation of a spherical and hemispherical charge of 1 $\mathrm{kg}$ TNT. Thus, all energies of detonation reported here range from a minimum value of $-3.21 \mathrm{MJ} \cdot \mathrm{kg}^{-1}$ [4] to a maximum value of $-4.832 \mathrm{MJ} \cdot \mathrm{kg}^{-1}$ [14]. The average value of the detonation energy in the literature is -4.4 $\mathrm{MJ} \cdot \mathrm{kg}^{-1}$

In the case of TNT, the detonation enthalpy of decomposition calculated by Kinney [6] underestimated the energy by approximately $40 \%$, whereas the decomposition calculated by K-J rule [1] overestimated the energies by a factor of 1.3 compared to the average value of -4.4 $\mathrm{MJ} \cdot \mathrm{kg}^{-1}$. Using calculations based on liquid water, the $\mathrm{S}-\mathrm{R}$ rule led to deviations from the mean value between $1.4 \%$ and $5.5 \%$. The difference of $1.4 \%$ is obtained by taking the enthalpy of formation given by Akhavan [2]. The modified K-W rules show differences on the order of $3.2 \%$ to $7.6 \%$. Greater differences are obtained by considering water as a gas in the calculations. Finally, for a reference enthalpy, the range of differences between calculations based on the Gibbs free enthalpy and the enthalpy of the reaction varies by a factor of 2 between the lower and upper bounds.

In the case of PETN, considering water as gas, the energy values ranged from $-5.667 \mathrm{MJ} \cdot \mathrm{kg}^{-1}$ [1] to -6.359 $\mathrm{MJ} \cdot \mathrm{kg}^{-1}$ [15], resulting in an average of $-6.06 \mathrm{MJ} \cdot \mathrm{kg}^{-1}$ (Table 4). Ornellas [16] reported a significantly higher value that was not taken into account in calculating the average. Scilly [1] obtained experimentally a detonation energy value of $-5.73 \mathrm{MJ} \cdot \mathrm{kg}^{-1}$. The S-R (or K-J) rules applied to the calculation of free energies correlates very well $(<1 \%)$ with this value for the enthalpies of formation reported in previous work [17-19]. For other data $[2,6,14]$, the differences range from $1.4 \%$ to $3 \%$. The differences in energy values calculated from the enthalpies of reaction are of the order of $3 \%$ to $7 \%$. However,

Table 3. Enthalpy of formation and entropy for TNT and PETN.

\begin{tabular}{|c|c|c|}
\hline TNT-H $\left(\mathrm{kJ} \cdot \mathrm{mol}^{-1}\right)$ & \multicolumn{2}{|c|}{$-26.00[2] ;-41.13[20] ;-54.40[6] ;-54.49[21] ;-59.47[17]$} \\
\hline TNT-S $\left(\mathrm{J} \cdot \mathrm{mol}^{-1} \cdot \mathrm{K}^{-1}\right)$ & \multicolumn{2}{|r|}{$272.00[6] ; 271.96[21] ; 554.00[20]$} \\
\hline PETN-H $\left(\mathrm{kJ} \cdot \mathrm{mol}^{-1}\right)$ & \multicolumn{2}{|c|}{$-477.05[2] ;-502.66[14] ;-514.63[6] ;-532.06[17] ;-538.50[18,22,23]$} \\
\hline \multicolumn{2}{|c|}{ PETN-S $\left(\mathrm{J} \cdot \mathrm{mol}^{-1} \cdot \mathrm{K}^{-1}\right)$} & $129.36[18]$ \\
\hline $\begin{array}{l}\text { Detonation Energy } \\
\left(\mathrm{MJ} \cdot \mathrm{kg}^{-1}\right)\end{array}$ & Experimental Value & Theoretical Value \\
\hline $\mathrm{H}_{2} \mathrm{O}$ Gas & $-5.73[1] ;-8.137[16]$ & $-5.949[17] ;-6.359[15] ;-6.276[24] ;-5.9[14] ;-5.8[9] ;-5.667[1]$ \\
\hline $\mathrm{H}_{2} \mathrm{O}$ Liquid & $-6.234[1] ;-6.322[17] ;-6.19,-6.24,-6.30[8]$ & $-6.404[17] ;-6.347[22] ;-5.792[2]$ \\
\hline
\end{tabular}


if water is considered in its liquid form, application of the $\mathrm{K}-\mathrm{W}$ rule is in better agreement with the average value, especially with the enthalpies calculated by Tarver [19]. For other values of the enthalpy of formation, the gap remains below 3\%. The free energies applied to the case of decomposition using the S-R (or K-J) rules have a difference of $10 \%$ compared to experimental values [ 1 , 8 ] or to the average value.

In conclusion, in the case of TNT, it is preferable to adopt the S-R rules based calculation methods with the assumption of liquid water using the thermochemical data of Akhavan [2] where the enthalpy of formation is lower. For PETN, it is preferable to use the K-W rules with the assumption of liquid water and the enthalpy of formation given by Tarver [19], which gives the best correlation with respect to the average value.

In the absence of thermochemical data for ANFO, it was not possible to carry out similar calculations to compute the detonation energy. Kinney [6] reported detonation energy of $-5.197 \mathrm{MJ} \cdot \mathrm{kg}^{-1}$.

\section{Blast Waves in Free Air}

\subsection{Characteristics of Blast Waves Resulting from Detonation}

The pressure profile over time of an ideal blast wave can be characterized by its rise time, the peak overpressure, the positive phase duration and the total duration (Friedlander wave). Thus, the change in pressure created by an explosion at a fixed distance $r$ from the center of the explosion can be schematized by the following profile (Figure 1).

In this diagram, $t_{a}$ is the arrival time of the wavefront, $\Delta P^{+}$is the positive overpressure, $\tau^{+}$is the duration of the positive phase, $I^{+}$is the positive momentum, $\Delta P^{-}$is the negative depression, $\tau^{-}$is the duration of the negative phase and $I^{-}$is the negative impulse. The impulse compression phase is calculated using the following formula:

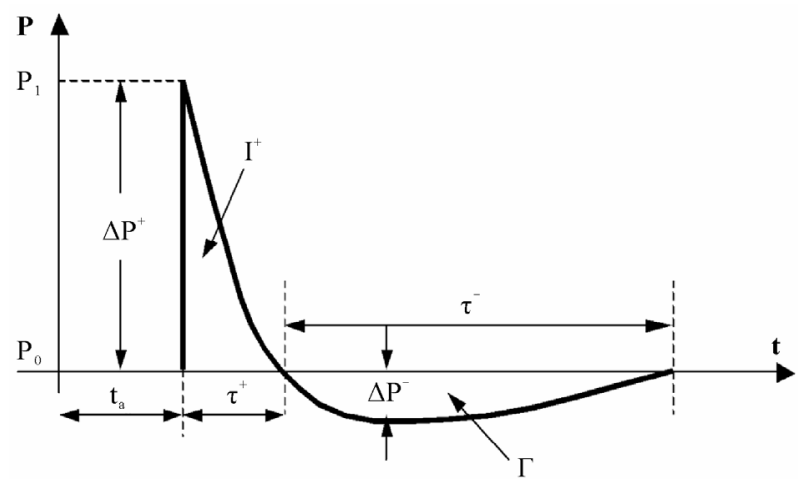

Figure 1. Pressure profile characteristic of the blast wave resulting from detonation.

$$
I^{+}=\int_{t_{a}}^{t_{a}+\tau^{+}} \Delta P^{+} \mathrm{d} t
$$

and the impulse of the rarefaction wave is given by the following:

$$
I^{-}=\int_{t_{a}+\tau^{+}}^{t_{a}+\tau^{+}+\tau^{-}} \Delta P^{-} \mathrm{d} t
$$

The terms of the compression wave and rarefaction wave are important for analyzing the response of the target under the action of the shock wave. The energy of explosion, the density of energy released (the energy volume of the load) and the power (the rate of release of energy) are the source parameters that determine the amplitude, duration and other features of the blast wave. The detonating explosives generate waves that are considered 'near-ideal' due to their high density compared to air, and therefore the energy released per unit of volume is significant.

The same analytical relationships have been established to calculate the characteristics of the blast wave as a function of distance (including pressure, duration and impulse of the positive and negative phases).

A review of these approaches is proposed here. In the context of this article, the study was limited to the parameters of pressure, impulse and the duration of the positive phase of the blast wave of explosive spherical charges in air, at high altitudes without ground effect.

Comparison of the main characteristics of blast waves in this study has been restricted to TM5-855 (CONWEP) [25] which supersedes TM5-1300 [26], AUTODYN code [27] and software ASIDE [28]. CONWEP allows the calculation of the effects of conventional weapons from the curves derived from TM5-855, "Fundamentals of Protective Design for Conventional Weapons" from the US Army Engineer Waterwaps. The calculations can be conducted for explosions at ground level or in the air. The AUTODYN software is a code for digital nonlinear dynamic analysis of unsteady shock waves, impact and the dynamic response of structures. In this study, calculations using AUTODYN were performed for spherical detonation of a $1 \mathrm{~kg}$ explosive charge (TNT, PETN and ANFO) at distance up to 20 meters. Simulations were made with an AUTODYN 1D model to refine the mesh (1-mm and $0.5-\mathrm{mm}$ ) over a length of 20 meters. Pressure gauges were regularly located and the pressure-time result files were processed to calculate the characteristic parameters ASIDE, with criminalistic vocation, combines the functionalities of a software and a data base. It is based on the observation of the damage and the elements of evidence collected during investigations of way to be able to evaluate the explosive load used. Contrary, ASIDE can provide an estimate of the damage if the na- 
ture and the quantity of the load are known or could be estimated.

\subsection{Evolution of the Positive Overpressure Blast Wave Incident on the Basis of Distance}

\subsubsection{Explosion Loads of TNT in Air}

In Figure 2 below, pressures are plotted on $\ln -\ln$ curves and are expressed in bar or $10^{5} \mathrm{~Pa}$, whereas on the abscissa, the reduced distances $Z$ are defined as the ratios of the distance from the point of explosion to the cubed root of the mass of the explosive charge $\left(Z=R \times M^{-1 / 3}\right)$ expressed in $\mathrm{m} \cdot \mathrm{kg}^{-1 / 3}$. It is the same for the relationships that are in this paper.

The calculations obtained with AUTODYN for a mesh size of $\mathrm{dh}=0.5 \mathrm{~mm}$ coincide with those for a mesh size of $\mathrm{dh}=1 \mathrm{~mm}$ and are in good agreement with the TM5855 calculation. In the near field $Z\left(\mathrm{~m} \cdot \mathrm{kg}^{-1 / 3}\right)<1$, the code ASIDE overlaps perfectly with the TM5-855, whereas in the median field $\left(1<Z\left(\mathrm{~m} \cdot \mathrm{kg}^{-1 / 3}\right)<10\right)$, significant differences are obtained. Beyond $10 \mathrm{~m} \cdot \mathrm{kg}^{-1 / 3}$, the ASIDE curve intersects the TM5-855 abacus then diverges. The curve obtained with ASIDE is not parallel to the other curves.

The complete results can be expressed as laws using either the forensics approach, i.e., by expressing the mass of the explosive (or reduced distance) as a function of the positive overpressure, or using the security approach, i.e., by expressing the overpressure as a function of reduced distance.

- Forensic Approach

TM5-855:

$$
\begin{aligned}
& 0.06<\Delta P\left(\times 10^{5} \mathrm{~Pa}\right)<58: \ln Z=0.9849 \\
& -0.4804(\ln \Delta P)+0.043(\ln \Delta P)^{2} \\
& -0.0071(\ln \Delta P)^{3}-0.0010(\ln \Delta P)^{4}
\end{aligned}
$$

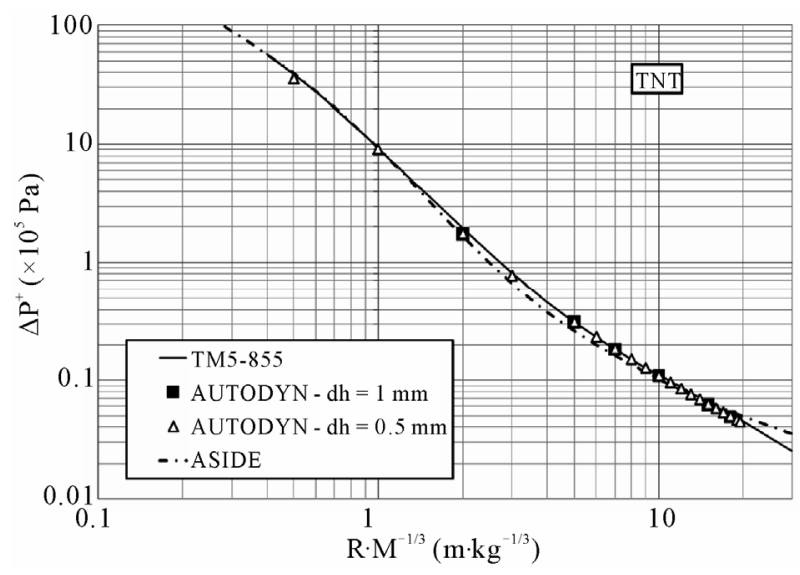

Figure 2. Overpressure as a function of reduced distance for explosions of spherical TNT charges in free air.
ASIDE:

$$
\begin{aligned}
& 2<\Delta P\left(\times 10^{5} \mathrm{~Pa}\right)<90: \ln Z=0.8409 \\
& -0.3100(\ln \Delta P)-0.0305(\ln \Delta P)^{2}
\end{aligned}
$$

$$
\begin{aligned}
& 0.03<\Delta P\left(\times 10^{5} \mathrm{~Pa}\right)<2: \ln Z=0.9091-0.4428(\ln \Delta P) \\
& +0.0426(\ln \Delta P)^{2}-0.0126(\ln \Delta P)^{3}+0.0004(\ln \Delta P)^{4}
\end{aligned}
$$

- Security Approach TM5-855:

$$
\begin{aligned}
& 0.4<Z\left(\mathrm{~m} \cdot \mathrm{kg}^{-1 / 3}\right)<16: \ln \Delta P=2.2375-2.2057(\ln Z) \\
& -0.1392(\ln Z)^{2}+0.1146(\ln Z)^{3}-0.0039(\ln Z)^{4}
\end{aligned}
$$

ASIDE:

$$
\begin{aligned}
& 0.3<\mathrm{Z}\left(\mathrm{m} \cdot \mathrm{kg}^{-1 / 3}\right)<2: \ln \Delta P=2.2411 \\
& -2.3065(\ln Z)-0.3646(\ln Z)^{2} \\
& 2<\mathrm{Z}\left(\mathrm{m} \cdot \mathrm{kg}^{-1 / 3}\right)<30: \ln \Delta P=2.4660 \\
& -3.1974(\ln Z)+0.5375(\ln Z)^{2} \\
& +0.0024(\ln Z)^{3}-0.0096(\ln Z)^{4}
\end{aligned}
$$

Note: In this paper, for a better readability of the curves, the reduced radial distance-axis is limited to the domain $(0.3,30) \mathrm{m} \cdot \mathrm{kg}^{-1 / 3}$. However, some laws are validated out of this range.

\subsubsection{Explosion Loads of PETN and ANFO in Air}

The evolution of overpressure as a function of reduced distance for the respective charges of PETN and ANFO is reported in Figure 3.

The simulations carried out with AUTODYN show no differences (Figure 3(a)) in the pressure for PETN of densities 0.88 and 1.77 and also correlate well with the calculated TM5-855 curve. In the range $Z\left(\mathrm{~m}^{\circ} \mathrm{kg}^{-1 / 3}\right)>5$, there is no difference between the two types of ANFO explosives (industrial and handmade) and the pressure results from ASIDE code are very well correlated with TM5-855. For ANFO, (Figure 3(b)) differences are obtained with the AUTODYN simulation for $Z<5 \mathrm{~m} \cdot \mathrm{kg}^{-1 / 3}$, and greater convergence is obtained for $Z>5 \mathrm{~m} \cdot \mathrm{kg}^{-1 / 3}$. Comparison with TNT shows that the PETN charge leads to greater pressure effects, although for ANFO, the effects are in the reverse direction. The energy equivalence will be greater than 1 for PETN and less than 1 for ANFO.

The polynomials obtained for PETN and ANFO from TM5-855 as part of the forensics and security procedures are summarized below.

- Forensic Approach 


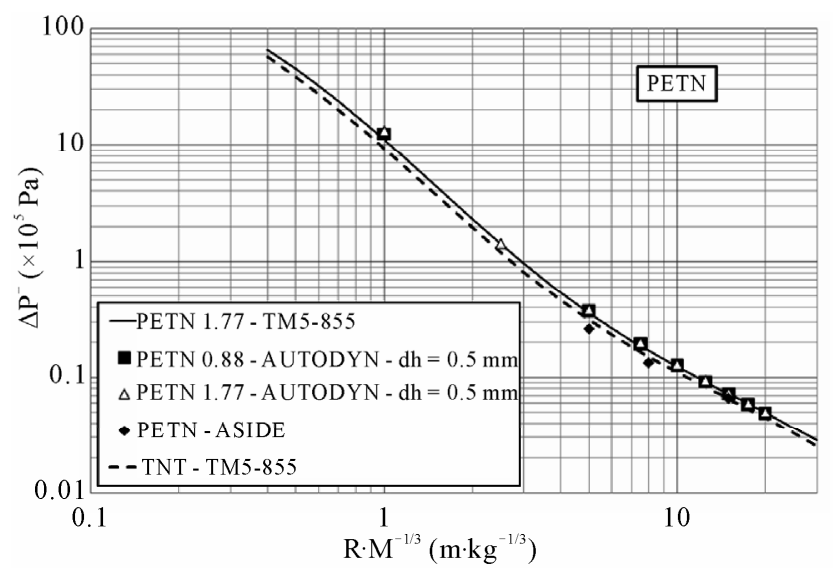

(a)

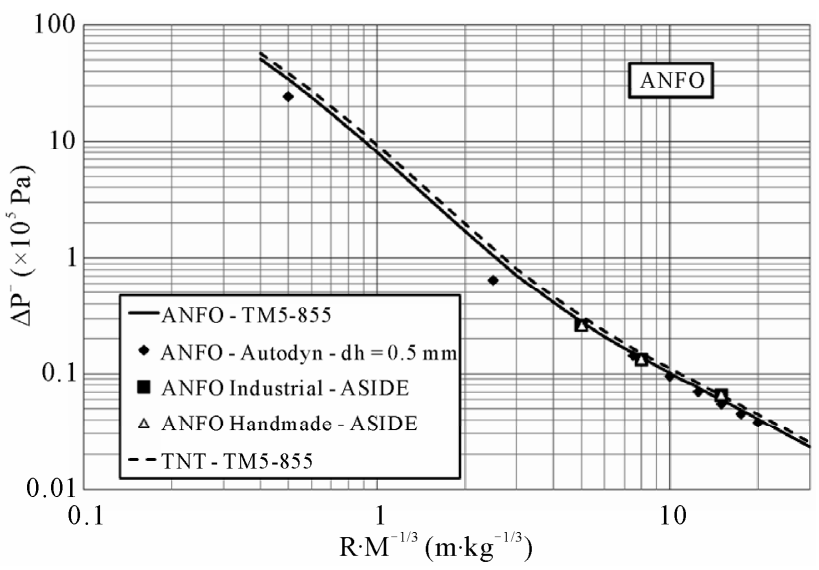

(b)

Figure 3. Overpressure spherical charges of PETN and ANFO as a function of reduced distance in free air.

PETN-TM5-855:

(10)

$$
\begin{aligned}
& 11<\Delta P\left(\times 10^{5} \mathrm{~Pa}\right)<65: \ln Z=0.8156 \\
& -0.2371(\ln \Delta P)-0.0421(\ln \Delta P)^{2} \\
& 0.02<\Delta P\left(\times 10^{5} \mathrm{~Pa}\right)<11: \ln Z=1.0755 \\
& -0.4397(\ln \Delta P)+0.0557(\ln \Delta P)^{2} \\
& -0.0163(\ln \Delta P)^{3}-0.0043(\ln \Delta P)^{4}
\end{aligned}
$$

ANFO-TM5-855:

$$
\begin{gathered}
0.1<\Delta P\left(\times 10^{5} \mathrm{~Pa}\right)<5: \ln Z=0.9303 \\
-0.4768(\ln \Delta P)+0.0344(\ln \Delta P)^{2}-0.0085(\ln \Delta P)^{3} \\
0.02<\Delta P\left(\times 10^{5} \mathrm{~Pa}\right)<1.7: \ln Z=0.7899 \\
-0.6296(\ln \Delta P)+0.0175(\ln \Delta P)^{2}
\end{gathered}
$$

- Security Approach PETN-TM5-855:

$$
\begin{aligned}
& 0.4<Z\left(\mathrm{~m} \cdot \mathrm{kg}^{-1 / 3}\right)<2: \ln \Delta P \\
& =2.4147-2.2208(\ln Z)-0.3184(\ln Z)^{2} \\
& 2<Z\left(\mathrm{~m} \cdot \mathrm{kg}^{-1 / 3}\right)<30: \ln \Delta P=2.4038 \\
& -2.1387(\ln Z)-0.3354(\ln Z)^{2} \\
& +0.2848(\ln Z)^{3}-0.0452(\ln Z)^{4}
\end{aligned}
$$

ANFO-TM5-855:

$$
\begin{aligned}
& 0.4<Z\left(\mathrm{~m} \cdot \mathrm{kg}^{-1 / 3}\right)<10: \ln \Delta P=2.0892 \\
& -2.2328(\ln Z)-0.1259(\ln Z)^{2} \\
& +0.1206(\ln Z)^{3}+0.0030(\ln Z)^{4}
\end{aligned}
$$

$$
\begin{aligned}
& 10<Z\left(\mathrm{~m} \cdot \mathrm{kg}^{-1 / 3}\right)<30: \ln \Delta P=1.6259 \\
& -2.4095(\ln Z)+0.4477(\ln Z)^{2}-0.0605(\ln Z)^{3}
\end{aligned}
$$

\subsection{Evolution of the Duration of the Incident Blast Wave as a Function of Distance in the Positive Phase}

The positive phase duration is typically reported as the cubed root of the mass of the explosive. The graph shown below in Figure 4 indicates that developments in positive phase durations are more difficult to characterize, although the overall trend shows that the duration positive phase increases with reduced distance. The duration also approaches an asymptote in the far and near field.

The simulations with AUTODYN show that the positive phase durations are underestimated compared to the references in TM5-855. In addition, there is a visibly large gap for short distances less than $3 \mathrm{~m} \cdot \mathrm{kg}^{-1 / 3}$.

Regardless of the explosive (i.e., PETN or ANFO), changes in the duration of the positive phase of the blast

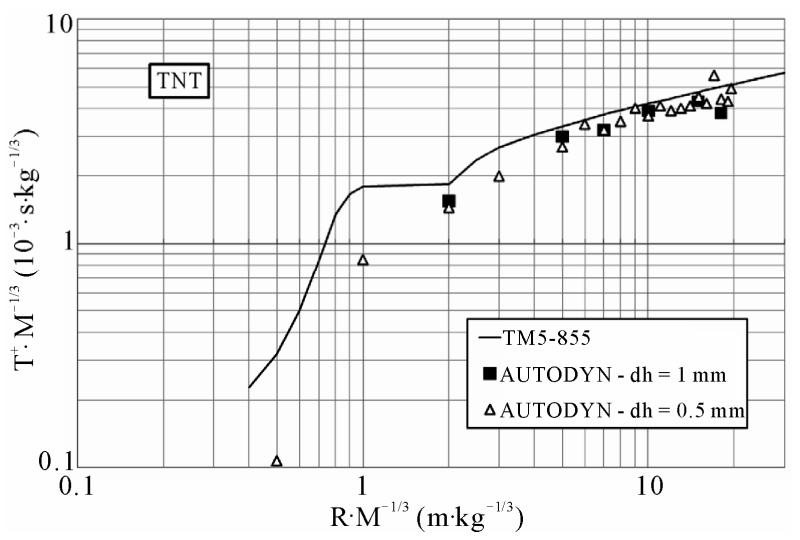

Figure 4. Duration of the reduced distance function for explosions of spherical TNT charges in free air. 
waves are not parallel to those of TNT. As shown in Figure 5, they intersect at $Z=2 \mathrm{~m} \cdot \mathrm{kg}^{-1 / 3}$. For PETN, regardless of the density chosen with AUTODYN, Figure 5(a) shows convergence with TM5-855 for $Z>5$ $\mathrm{m} \cdot \mathrm{kg}^{-1 / 3}$. However, the calculated durations are lower than those for TNT, while the application of TM5-855 for PETN gives values that are $T^{+} / \sqrt[3]{M}$ higher. This leads to a contradiction in the equivalent energy.

Developments in terms of the positive phase of the blast wave following the detonation of charges of TNT, PETN and ANFO from the TM5-855 can be written as a polynomial using either the forensic approach (Table 5) or the security approach (Table 6). The coefficients of polynomial laws are given in tables.

- Forensic approach (Table 5)

- Security Approach (Table 6)

\subsection{Evolution of the Positive Impulse for the Incident Blast Wave Based on Distance}

The studies mentioned above describe the evolution of the impulse that follows an explosion. Generally, it is reduced to the cube root of the mass of the explosive. In the expressions given below, the impulse is expressed in

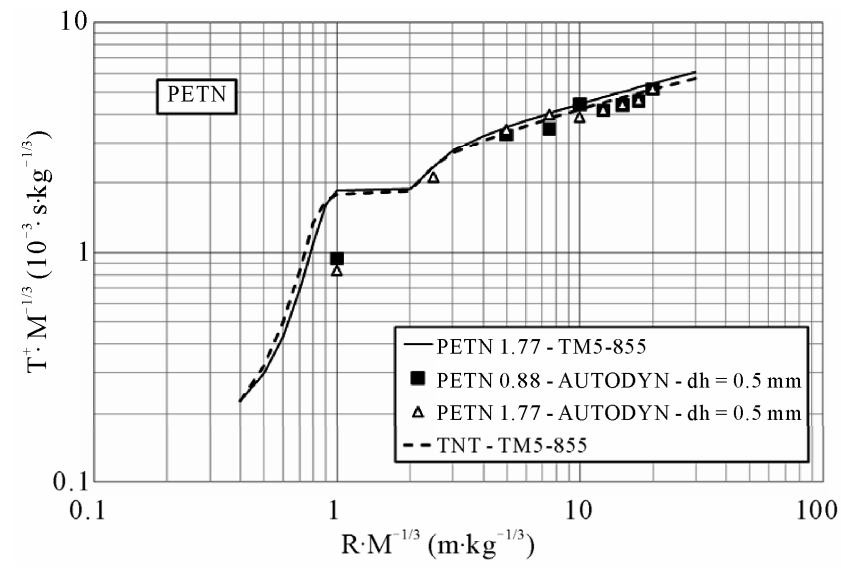

(a)

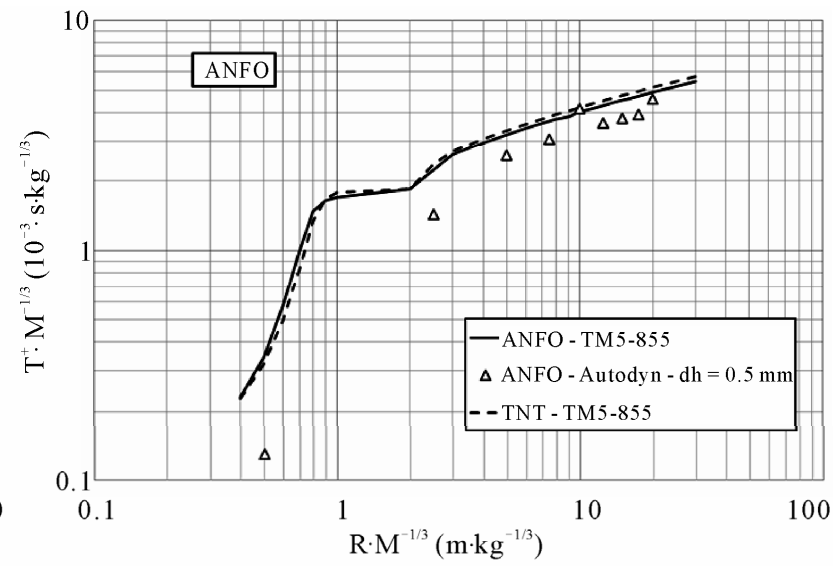

(b)

Figure 5. Positive phase duration as a function of reduced distance for explosions of spherical PETN and ANFO charges in free air.

Table 5. Polynomials for the duration of positive phase-forensic approach.

\begin{tabular}{|c|c|c|c|c|c|}
\hline \multirow{2}{*}{$T^{+} / \sqrt[3]{M}\left(\times 10^{-3} \mathrm{~s} \cdot \mathrm{kg}^{-1 / 3}\right)$} & \multicolumn{5}{|c|}{$\ln Z=\mathrm{a}+\mathrm{b}\left(\ln T^{+} / \sqrt[3]{M}\right)+\mathrm{c}\left(\ln T^{+} / \sqrt[3]{M}\right)^{2}+\mathrm{d}\left(\ln T^{+} / \sqrt[3]{M}\right)^{3}+\mathrm{e}\left(\ln T^{+} / \sqrt[3]{M}\right)^{4}$} \\
\hline & a & $\mathrm{b}$ & $\mathrm{c}$ & $\mathrm{d}$ & $\mathrm{e}$ \\
\hline TNT-TM5-855 $0.2 \leq T^{+} / \sqrt[3]{M} \leq 6$ & -0.3136 & 0.6328 & 0.59801 & 0.2305 & -0.0474 \\
\hline PETN-TM5-855 $0.2 \leq T^{+} / \sqrt[3]{M} \leq 6$ & -0.2625 & 0.2750 & 0.1162 & 0.1533 & 0 \\
\hline ANFO-TM5-855 $0.2 \leq T^{+} / \sqrt[3]{M} \leq 6$ & -0.4204 & 0.8313 & 0.6577 & 0.1492 & -0.0251 \\
\hline
\end{tabular}

Table 6. Polynomials for the duration of positive phase-security approach.

\begin{tabular}{|c|c|c|c|c|c|}
\hline \multirow{2}{*}{$Z\left(\times 10^{-3} \mathrm{~s} \cdot \mathrm{kg}^{-1 / 3}\right)$} & \multicolumn{5}{|c|}{$\ln \left(T^{+} / \sqrt[3]{M}\right)=\mathrm{A}+\mathrm{B}(\ln Z)+\mathrm{C}(\ln Z)^{2}+\mathrm{D}(\ln Z)^{3}+\mathrm{E}(\ln Z)^{4}$} \\
\hline & A & B & $\mathrm{C}$ & $\mathrm{D}$ & $\mathrm{E}$ \\
\hline \multicolumn{6}{|l|}{ TNT-TM5-855 } \\
\hline $0.4 \leq Z \leq 1$ & 0.5819 & -0.5423 & -11.1572 & -11.9941 & -3.4023 \\
\hline $1 \leq Z \leq 30$ & 0.5511 & 0.0271 & 0.4937 & -0.2079 & 0.0268 \\
\hline \multicolumn{6}{|l|}{ PETN-TM5-855 } \\
\hline $0.4 \leq Z \leq 1$ & 0.6353 & 1.4681 & -3.8373 & 0.0049 & 3.5874 \\
\hline $1 \leq Z \leq 30$ & -0.0225 & 1.2575 & -0.3619 & 0.0444 & 0 \\
\hline \multicolumn{6}{|l|}{ ANFO-TM5-855 } \\
\hline $0.4 \leq Z \leq 1$ & 0.5283 & -0.5060 & -5.5012 & 1.4778 & 4.7291 \\
\hline $1 \leq Z \leq 30$ & 0.5032 & 0.1396 & 0.3617 & -0.1572 & 0.0204 \\
\hline
\end{tabular}


$\mathrm{Pa} \cdot \mathrm{s} \cdot \mathrm{kg}^{-1 / 3}$.

Figure 6 shows that the changes remain parallel and even though the dispersion of the AUTODYN simulation results affects the impulse, the results correlate well with the TM5-855 data.

As for the positive phase duration, the impulses obtained by the AUTODYN simulation overlap the calculation for TNT-TM5-855 and are parallel to the PETNTM5-855 calculations regardless of PETN density. For ANFO, the results lead to significant differences and are under-estimated than the referenced abacus TM5-855 (Figure 7).

Polynomial laws in the $\ln -\ln$ deductions from TM5855 are defined for the forensic and security approaches in Tables 7 and $\mathbf{8}$, respectively.

- Forensic approach (Table 7)

- Security Approach (Table 8)

\section{TNT Equivalents}

The net weight of the explosive is a basic parameter for estimating safety in the manufacturing of fireworks and storage of ammunition. For this, we must know the TNT equivalent of explosives, which can be determined using

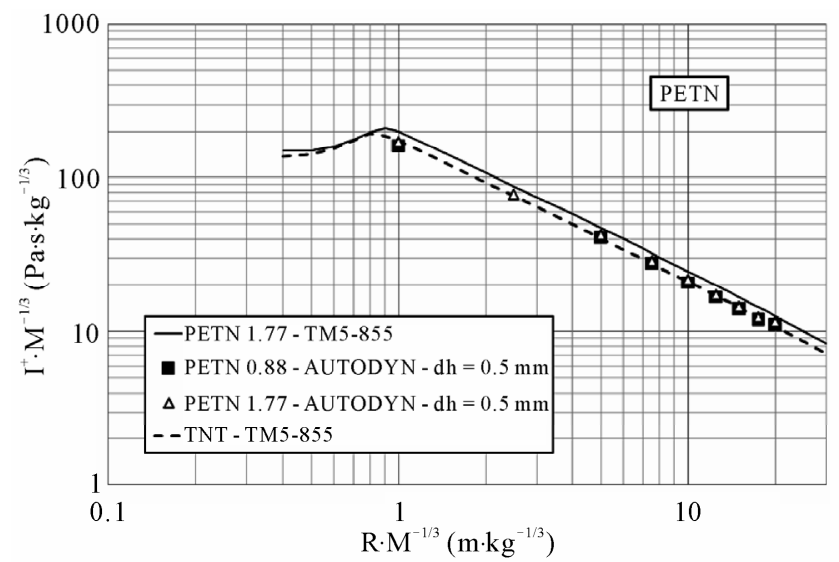

(a)

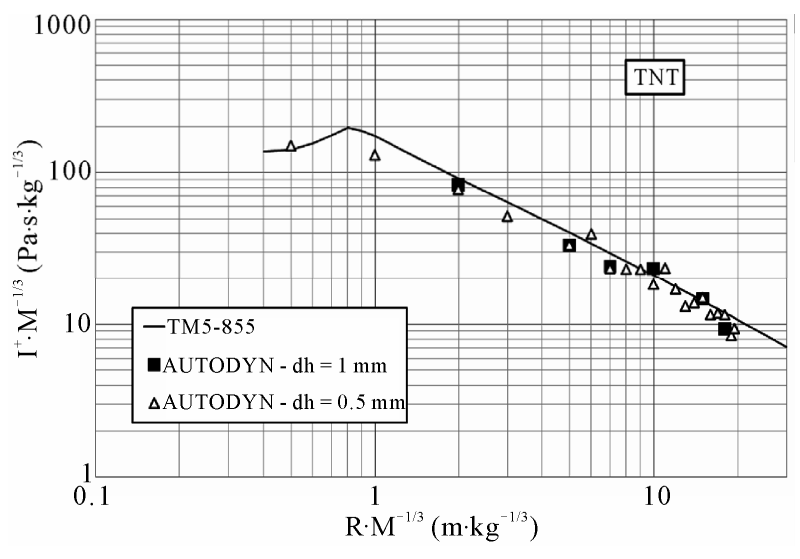

Figure 6. Positive impulse as a function of reduced distance for explosions of spherical TNT charges in free air.

Table 7. Polynomials for the positive impulse-Forensic approach.

\begin{tabular}{|c|c|c|}
\hline \multirow{2}{*}{$I^{+} / \sqrt[3]{M}\left(\mathrm{~Pa} \cdot \mathrm{s} \cdot \mathrm{kg}^{-1 / 3}\right)$} & \multicolumn{2}{|c|}{$\ln Z=\mathrm{a}+\mathrm{b}\left(\ln I^{+} / \sqrt[3]{M}\right.$} \\
\hline & a & $\mathrm{b}$ \\
\hline TNT-TM5-855 $7 \leq I^{+} / \sqrt[3]{M} \leq 175$ & 5.4242 & -1.0238 \\
\hline PETN-TM5-855 $8 \leq I^{+} / \sqrt[3]{M} \leq 200$ & 5.6005 & -1.0291 \\
\hline ANFO-TM5-855 $6 \leq I^{+} / \sqrt[3]{M} \leq 155$ & 5.2809 & -1.0200 \\
\hline
\end{tabular}

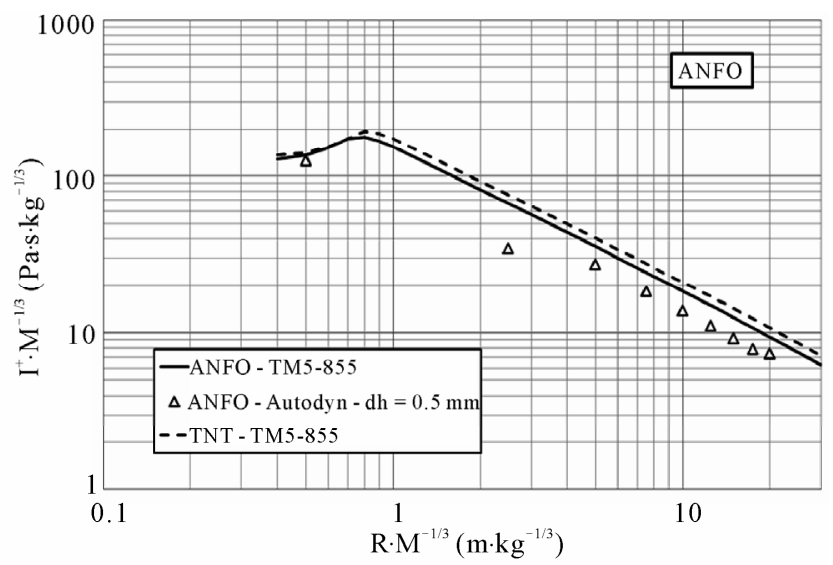

(b)

Figure 7. Positive impulse as a function of reduced distance for explosions of PETN and ANFO spherical charges in free air.

Table 8. Polynomials for the positive impulse-security approach.

\begin{tabular}{|c|c|c|c|c|}
\hline \multirow{2}{*}{$Z\left(\times 10^{-3} \mathrm{~s} \cdot \mathrm{kg}^{-1 / 3}\right)$} & \multicolumn{4}{|c|}{$\ln \left(I^{+} / \sqrt[3]{M}\right)=\mathrm{A}+\mathrm{B}(\ln Z)+\mathrm{C}(\ln Z)^{2}+\mathrm{D}(\ln Z)^{3}$} \\
\hline & A & B & $\mathrm{C}$ & $\mathrm{D}$ \\
\hline \multicolumn{5}{|l|}{ TNT-TM5-855 } \\
\hline $0.4 \leq Z \leq 1$ & 5.1627 & -1.1569 & -4.0749 & -2.760 \\
\hline $1 \leq Z \leq 30$ & 5.1629 & -0.9163 & 0 & 0 \\
\hline \multicolumn{5}{|l|}{ PETN-TM5-855 } \\
\hline $0.4 \leq Z \leq 1$ & 5.3108 & -0.3971 & -2.7404 & -2.1359 \\
\hline $1 \leq Z \leq 30$ & 5.3008 & -0.9069 & 0 & 0 \\
\hline \multicolumn{5}{|l|}{ ANFO-TM5-855 } \\
\hline $1 \leq Z \leq 30$ & 5.0427 & -0.9207 & 0 & 0 \\
\hline
\end{tabular}


several approaches. Generally, the TNT equivalent is the mass of TNT that provides an equal amount of energy during the explosion as the unit mass of the explosive in question. Specifically, the TNT equivalent is defined as the ratio of the mass of TNT to the mass of the explosive that leads to the same amplitude of a parameter of the blast wave (pressure or impulse) at the same radial distance for each charge assuming the scaling laws of Sachs and Hopkinson. The equivalent mass of pressure [29] for an explosive is then given as follows:

$$
E_{P}-T N T=\frac{M_{T N T}}{M}=\left(\frac{Z}{Z_{T N T}}\right)_{\text {Pcst }}^{3}
$$

where $Z$ is the reduced distance. A similar approach is conducted for the equivalent mass of impulse as follows:

$$
E_{I}-T N T=\frac{M_{T N T}}{M}=\left(\frac{Z}{Z_{T N T}}\right)_{\text {Icst }}^{3}
$$

However, when the impulses are reported as a cubed root of the mass, the equivalent impulses can be obtained by sliding the curves along the first diagonal. Esparza [29] conducted a study of several condensed explosives (Composition B, PBX-9404, PETN, TNT, PBX 9501, PBX 9502) and presented the average values of an equivalent TNT pressure range of 0.9 to 1.7 for these explosives, whereas the impulses, in terms of TNT equivalent, range from 0.6 to 1.2 . This is probably the easiest method, but it only applies for explosives with the same geometry.

However, Gelfand [9] defines the energy equivalent of TNT as the ratio of the detonation energy of an explosive and the detonation energy of TNT.

Taking into account the equation of detonation products, it can be shown that the effects of detonation are influenced by the basic parameters of detonation speed, pressure, detonation energy and the number of moles of gaseous detonation products. These values can be obtained from thermochemical calculations and it is possible to obtain an average value.

$$
E-T N T=k_{1} \times \frac{n_{H E}}{n_{T N T}}+k_{2} \times \frac{E_{H E}}{E_{T N T}}+k_{3} \times \frac{P_{H E}}{P_{T N T}}+k_{4} \times \frac{D_{H E}}{D_{T N T}}
$$

where $k_{1}, k_{2}, k_{3}$ and $k_{4}$ are empirical coefficients obtained experimentally [30].

The difficulty of estimating a single value for TNT equivalents is confirmed by Peugeot et al. [31], who describe the parameters influencing the equivalent value, namely the composition of the material energy, the distance and the geometry of the load. If the energy equivalent cannot be measured or estimated, then a TNT equivalent energy factor of 1.4 leads to a reasonable and conservative estimate of the equivalent TNT mass for every unknown explosive in accordance with the Allied Ammunition Storage and Transport Publication [32].

Formby and Wharton [33] and Wharton et al. [34] based their calculation on the TNT equivalent used in the Esparza approach for other types of condensed explosives and identified linear trends of TNT equivalents in terms of pressure and impulse as a function of reduced distance.

Regarding the explosives studied in this work, the development of overpressure and impulse as a function of reduced distance for PETN and ANFO are parallel to those of TNT. Therefore, TNT equivalent means can easily be deduced for each of the characteristic parameters of the blast wave with the exception of the positive duration.

- For overpressure, TNT energy equivalents of 1.14 and 0.90 are obtained for PETN and ANFO, respecttively, by sliding the PETN or ANFO pressure curves along the abscissa $Z$.

- For duration and impulse positive phase, the parameters are reduced to the cubed root of mass, and thus, the curves of PETN and ANFO are slid along the diagonal. Impulse energy equivalents of 1.15 and 0.90 are obtained for PETN and ANFO, respectively. However, in case of reduced duration an average equivalent TNT cannot be obtained because the curve of the explosive is either above or below the curve corresponding to TNT (Figure 5). There are two emerging areas for which it is possible to define a TNT equivalent. In the case of PETN, for $Z<0.9$ $\mathrm{m} \cdot \mathrm{kg}^{-1 / 3}$ the equivalent is 0.95 (Figure 5(a)) and for $Z>$ $5 \mathrm{~m} \cdot \mathrm{kg}^{-1 / 3}$ it is 1.06. In the case of ANFO (Figure 5(b)), the equivalent is 1.1 if $Z \leq 0.9 \mathrm{~m} \cdot \mathrm{kg}^{-1 / 3}$.

- The TNT equivalent energies obtained in this study are in good agreement with values reported in the literature (Table 9) in terms of pressure and impulse for ANFO. In case of PETN, the calculated TNT equivalent is smaller than the reported values (Table 9).

\section{Conclusions}

First, the computation of the detonation energy reported in this study has permitted us to compare different decomposition rules and thermodynamic data to underline the energy discrepancy for the three explosives studied (TNT, PETN, ANFO). In addition, the computation demonstrates the importance of clarifying the choice between the theoretical and experimental conditions.

Second, this study has identified the analytical solutions and the available abacus to estimate the effects of exploding pyrotechnic charges in terms of the overpressure, duration and impulse of the positive phase. Comparison of the main characteristics of blast waves in this study is focused on the TM5-855 (CONWEP), AUTO 
Table 9. TNT equivalent energies obtained in this study.

\begin{tabular}{cccc}
\hline \multirow{2}{*}{ Explosive } & \multicolumn{2}{c}{ TNT Equivalent } & \\
\cline { 2 - 4 } & Pressure & Impulse & Global \\
\hline PETN & $1.27[15,25,32,35] ; 1.33,1.45-1.73[9]$ & $1.28[9]$ \\
ANFO & $0.82[15,25,35] ; 0.83[32] ; 0.83$ for DP $=2.07$ at 13.8 bar and 0.59 for DP $>13.8$ bar $[36]$ & $0.82[1] 0.70[36]$ & $0.75[9]$ \\
\hline
\end{tabular}

DYN and ASIDE codes.

Comparison with TNT shows that PETN charges lead to higher pressures than TNT, whereas ANFO shows lower pressures.

AUTODYN simulations show that the effects of ANFO do not correlate well in terms of the duration and impulse. Therefore, the simulation of ANFO charges detonation must be examined with caution, and for example in a next step it is possible to consider a refined mesh, the choice of the state equation and the complex composition of ANFO.

Polynomial laws have been established based on two approaches, one forensic-based and the other securitybased. In the first, the reduced distance is expressed in terms of characteristic quantities of the explosive and in the second, the quantities of the explosive are expressed in terms of reduced distance.

\section{References}

[1] N. F. Scilly, "Measurement of the Explosive Performance of High Explosives," Journal of Loss Prevention in the Process Industries, Vol. 8, No. 5, 1995, pp. 265-273. doi:10.1016/0950-4230(95)00031-U

[2] J. Akhavan, "The Chemistry of Explosive," 2nd Edition, Royal Society of Chemistry (Great Britain), 2004.

[3] A. Lannoy, "Effet des Explosions sur les Structures, Extrapolation de l'Abaque du TM5-1300," EDF, Dir. Etudes et Recherches, 1979.

[4] W. S. Filler, "Post Detonation and Thermal Studies of Solid HIgh Explosives in a Closed Chamber," 6th International Symposium on Coal Combustion, Yale University, New Haven, 1956, pp. 648-657.

[5] DoD standard TNTe, 1998. http://www.fas.org/man/dod,101/navy/docs/es310/chemis try/chemistry.htm

[6] G. F. Kinney and K. J. Graham, "Explosives Shocks in Air," 2nd Edition, Springer-Verlag, Berlin, 1985.

[7] F. P. Lees, "Loss Prevention in the Process Industries, Hazard Identification, Assessment and Control, Vol. 2," 2nd Edition, Butterworth Heinemann, Oxford, 1996.

[8] Y. Tongchang, Y. Menchao and W. Jianling, "Determination of Heats of Detonation and Influence of Components of Composite Explosives on Heats of Detonation of High Explosives," Journal of Thermal Analysis, Vol. 44, No. 6, 1995, pp. 1347-1356. doi:10.1007/BF02549223

[9] B. Gelfand and M. Silnikov, "Blast Effects Caused by
Explosions" United States Army, European Research Office of the US Army, London, 2004.

[10] W. E. Baker, "Explosions in Air," University of Texas Press, Austin, 1973.

[11] H. Pförtner, "Gas Cloud Explosions and Resulting Blast Effects," Nuclear Engineering and Design, Vol. 41, No. 1, 1977, pp. 59-67. doi:10.1016/0029-5493(77)90094-2

[12] S. Trélat, "Impact de Fortes Explosions sur les Bâtiments Représentatifs d'Une Installation Industrielle," Thèse de Doctorat, l'Université d'Orléans, Orléans, 2006.

[13] M. Omang, S.O. Christensen, S. Borve and J. Trulsen, "Height of Burst Explosions: A Comparative Study of Numerical and Experimental Results," Journal Shock Waves, Vol. 19, No. 2, 2009, pp. 135-143. doi:10.1007/s00193-009-0196-8

[14] N. Kubota, "Propellants and Explosives," 2nd Edition, Wiley-VCH, Weinheim, 2007.

[15] G. Parmentier, "Synthèse des Résultats Expérimentaux Relatifs aux Détonations d'Explosifs Sphériques,'Institut Franco-Allemand de Recherche de Saint-Louis, 1993.

[16] J. D. Ornellas, "The Heat and Products of Detonation of Cyclotatramethylenetetranitramine, 2,4,6-Trinitrotoluene, Nitromethane, and Bis[2,2-dinitro-2-fluoroethyl]formal," Journal Physical Chemistry, Vol. 72, No. 7, 1968, pp. 2390-2394. doi:10.1021/j100853a019

[17] R. Meyer, "Explosives," 3rd Edition, VCH-Verlag, Weinheim, 1987.

[18] National Institute of Standards and Technology, National Institute of Standards and Technology. www.nist.gov/

[19] C. M. Tarver, T. D. Tran and R. E. Whipple, "Thermal Decomposition of Pentaerythritol Tetranitrate," Propellants Explosives Pyrotechnics, Vol. 28, No. 4, 2003, pp. 189-193. doi:10.1002/prep.200300004

[20] American Society for testing and Materials (ASTM), The ASTM Computer Program for Chemical Thermodynamic and Energy Release Evaluation CHETAH 7.3, 2001.

[21] NASA Lewis Research Center. http://www.me.berkeley.edu/gri_mech/data/thermo_table. $\underline{\mathrm{html}}$

[22] P. W. Cooper, "Explosives Engineering," Wiley-VCH, Weinheim, 1996.

[23] M. Finger, E. Lee, F. H. Helm, B. Hayes, H. Horning, R. McGuine, M. Kahara and M. Guidry, "The Effects of Elemental Composition on the Detonation Behavior of Explosives," Sixth Symposium (International) on Detonation, ACR-221, 1976, p. 710.

[24] J. Yinon and S. Zitrin, "Modern Methods and Applica- 
tions in Analysis of Explosive," Wiley, Hoboken, 1996.

[25] TM5-855-1, "Fundamentals of Protective Design for Conventional Weapons," US Department of the Army, Washington DC, 1987.

[26] TM5-1300, "The Design of Structures to Resist the Effects of Accidental Explosions," Technical Manual, US Department of the Army, the Navy and the Air Force, Washington DC, 1990,

[27] AUTODYN, Software for Non-Linear Dynamics, Proprietary to ANSYS.

[28] ASIDE, Forensic Software Database for Crime Scene Investigation, Proprietary of IRCGN.

[29] E. D. Esparza, "Blast Measurements and Equivalency for Spherical Charges at Small Scaled Distances," International Journal of Impact Engineering, Vol. 4, No. 1, 1986, pp. 23-40. doi:10.1016/0734-743X(86)90025-4

[30] R. Jeremié and Z. Bajié, "An Approach to Determining the TNT Equivalent of High Explosives," Scientific Technical Review, Vol. 56, No.1, 2006, pp. 58-62.

[31] F. Peugeot, E. Deschalbault and P. F. Péron, "TNT Equivalency: Misconceptions and Reality, Munitions Safety Information Analysis Center," Munitions Safety
Information Analysis Center (MSIAC) Unclassified, Report L-132, October 2006.

[32] Allied Ammunition Storage and Transport Publication (AASTP), 4, Explosives Safety Risks Analysis, Part II, AC/258(ST)WP/221, 2003.

[33] S. A. Formby and R. K. Wharton, "Blast Characteristics and TNT Equivalence Values for Some Commercial Explosives Detonated at Ground Level," Journal of Hazardous Materials, Vol. 50, No. 2-3, 1996, pp. 183-198. doi:10.1016/0304-3894(96)01791-8

[34] R. K. Wharton, S. A. Formby and R. Merrifield, "Airblast TNT Equivalence for a Range of Commercial Blasting Explosives," Journal of Hazardous Materials, Vol. 79, No. 1-2, 2000, pp. 31-39. doi:10.1016/S0304-3894(00)00168-0

[35] P. Naz, "Etude de Souffle des Têtes Explosives. Etude Bibliographique," Institut Franco-Allemand de Recherche de Saint-Louis, Saint-Louis, 2005.

[36] J. Mory, R. Branka, "Les Equivalents TNT des Explosifs Intentionnels et des Produits Chimiques Condensés Solides ou Liquides à Risque d'Explosion,"Europyro 8th Congrès International de Pyrotechnie, Saint-Malo, 23-27 June 2003, pp. 407-440. 